\title{
Analysis of Spiral Lattice Girder Shape in preparation for HSR Speed Increase
}

\author{
Ki-Young Eum ${ }^{\dagger}$, Jee-Ha Lee*, Young-Kon Park*, Jangho Yun* and Seongwoon Jeong*
}

\begin{abstract}
A spiral lattice girder-reinforced Bi-block sleeper which has enhanced durability against increasingly growing impact force and vibration by wheel load and improved structural performance while train runs at $350 \mathrm{~km} / \mathrm{h}$ high speed is hereby proposed. The section of a spiral lattice girder has stable and superior structural performance thanks to its confinement effect. To compare and analyze the structural performance of spiral lattice girder-reinforced bi-block sleeper, strain and stress distribution were evaluated after applying same load condition as existing triangular lattice girder-reinforced biblock sleeper, and to compare the structural performance of triangular lattice girder and spiral lattice girder, structural analysis of lattice girder was performed separately. As a result, a spiral lattice girder proved to have had superior structural characteristics to bi-block sleeper, and furthermore as a result of evaluating the fastener interface and constructibility with shape-improved lattice girder, no interference with existing railroad structure was found and in terms of cost efficiency, a spiral lattice girder appeared to be superior to existing lattice girder
\end{abstract}

Keywords : High speed railroad, Spiral lattice girder, Bi-block sleeper, Confinement effect, Durability

\section{Introduction}

\subsection{Need for improving the shape}

In a bid to maximize such advantage of high speed railroad (HSR) as eco-friendly and mass transport, competition to increase the speed has been emerged globally and domestically, the train running $400 \mathrm{~km} / \mathrm{h}$ or faster has been developed and technical development in preparation for HSR system at $350 \mathrm{~km} / \mathrm{h}$ or faster has been accelerated. Particularly in some HSR-manufactured countries, railroad industry has been promoted as the main target at the government-level to take initiative in global HSR market, causing severe competition.

Technical development of HSR infrastructure for HSR operation has also been accelerated. HSR system shall secure the design \& construction technologies including such infrastructure as track, tunnel or bridge, besides the

\footnotetext{
Corresponding author: High-Speed Railroad Infrastructure Research Team, KRRI E-mail : kyeum@krri.re.kr

* High-Speed Railroad Infrastructure Research Team, KRRI

(C) The Korean Society for Railway 2013

http://dx.doi.org/10.7782/IJR.2013.6.4.160
}

rolling stock. Currently, next-generation railroad vehicle (HEMU-430x) has been developed and under test \& commissioning and the effort to develop the track infrastructure technologies have been made. The maximum operation speed of the trains including Gyeongbu HSR in Korea and in Europe, USA, Japan and China is around $300 \mathrm{~km} / \mathrm{h}$ and they have built concrete sleeper developed to accommodate such speed level.

Various sleeper structures are used for train running at $300 \mathrm{~km} / \mathrm{h}$ level and the types are mostly a single block sleeper which has same shape as wooden type and a biblock sleeper having a block-type part for rail support. The sleeper for HSR is mostly reinforced concrete sleeper (reinforced with steel mesh or rebar) for the purpose of reducing maintenance cost.

But the sleeper currently used for HSR track was designed for $300 \mathrm{~km} / \mathrm{h}$ level, which means, it would not be appropriate for the speed more than $350 \mathrm{~km} / \mathrm{h}$. When a train runs at $350 \mathrm{~km} / \mathrm{h}$ or faster, impact force and vibration on sleeper through rail by wheel load would rapidly increase and moreover repeated cycle of wheel load on sleeper through rail would increase in proportion to speed, causing durability to be weakened inevitably by fatigue failure. 
Excessive impact force and vibration have direct effect on sleeper, causing the cracks in sleeper which supports the rail which results in deteriorated durability of the sleeper and frequent replacement. Reduced life cycle of the sleeper causes the maintenance cost to go up which is unfavorable in terms of cost efficiency.

A spiral lattice girder-reinforced bi-block is hereby proposed to ensure the sleeper will maintain the sufficient durability against the increasingly growing impact force and vibration in line with increased train speed more than $350 \mathrm{~km} / \mathrm{h}$.

\subsection{Summary of spiral lattice girder}

Existing sleeper is reinforced with triangular lattice girder for concrete block reinforcement and connection between blocks. A triangular lattice girder has the section with open bottom and thus it serves the spacer which maintains the interval of main horizontal reinforcement which is fixed to top and bottom of triangular lattice, a spiral lattice girder reinforced with spiral lattice has the section in closed round shape with vertically-extended section enveloping the concrete structure so that it serves the spacer which maintains the interval of main horizontal reinforcement as well as absorbs the impact and vibration from the vehicle running on rail. A continuous spiral lattice structure has stable and superior structural function to uniformly distribute the vehicle load from the rail to the ground, which is attributable to confinement effect while spiral lattice envelops and combines the concrete inside. Confinement effect of spiral lattice girder increases the compressive strength of concrete, thereby further enhancing the structural.

Comparison in shape between triangular lattice girder biblock sleeper and spiral lattice girder bi-block for HSR is made as follows.

\section{Improvement of Lattice Girder Shape (Proposed)}

\subsection{Characteristic of spiral lattice girder}

Concrete inside continuous spiral structure receives compressive strength while being confined by spiral lattice and thus confinement effect is naturally created. As spiral lattice with steel wire having high tensile strength and concrete with high compressive strength are confined each other, the greater the compressive strength the higher the constraint effect in proportion.

Compressive force is generated by wheel load at all times inside the sleeper and thus the sleeper reinforced with spiral lattice has the effect inside the sleeper that generates composite core in round section by steel-concrete compos-

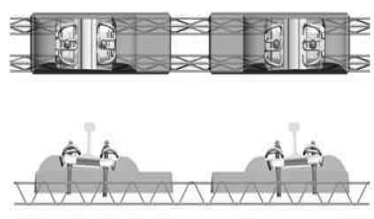

(a) Triangular lattice

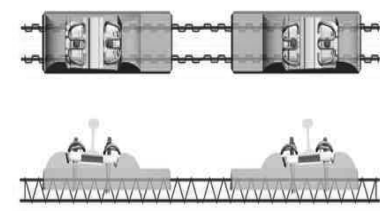

(b) Spiral lattice
Fig. 1 Comparison of bi-block sleepers

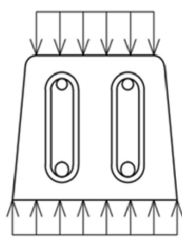

Compressive Strength

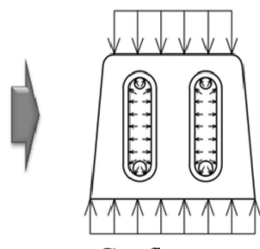

Confinement Effect

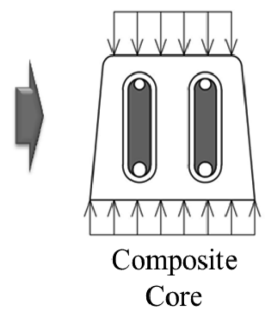

Fig. 2 Formation of Composite Core
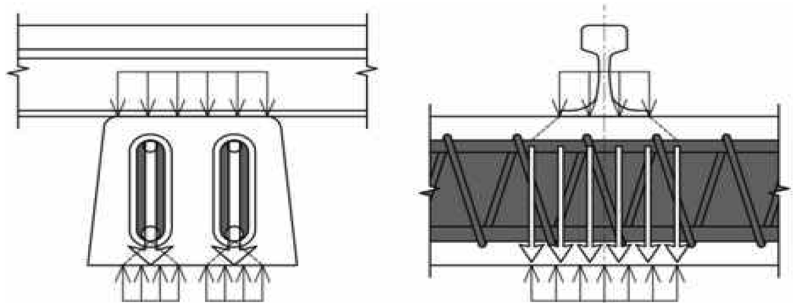

Fig. 3 Conveying compressive force through composite core

ite of spiral lattice and concrete as shown in Fig 2. Composite core confined by spiral lattice has the relatively greater rigidity than surrounding non-composite concrete.

As seen in Fig 3, composite core functions to convey the compressive force from rail to the ground. Thus it could be optimized by reinforcing the bottom of composite core with flexural reinforcement to make it cost efficient structural reinforcement.

Wheel load conveyance mechanism of spiral lattice-reinforced sleeper is as follows.

1) Wheel load on top of rail 2) Wheel load conveyed to concrete sleeper through rail bottom 3) Concrete sleeper receives compressive force while spiral lattice confines the concrete inside 4) Confinement effect is generated as spiral lattice with tensile strength-resistant steel wire (rebar) and compressive force-resistant concrete confine each 5) A composite core in round section formed with spiral lattice and concrete is formed 6) Load is distributed to the ground through composite core.

\subsection{Comparison and analysis of structural performance of improved bi-block sleeper}

To compare the structural performance of spiral lattice- 


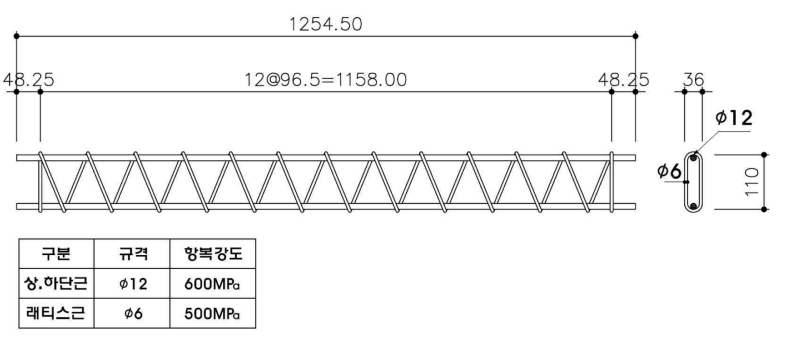

(a) Spiral lattice girder

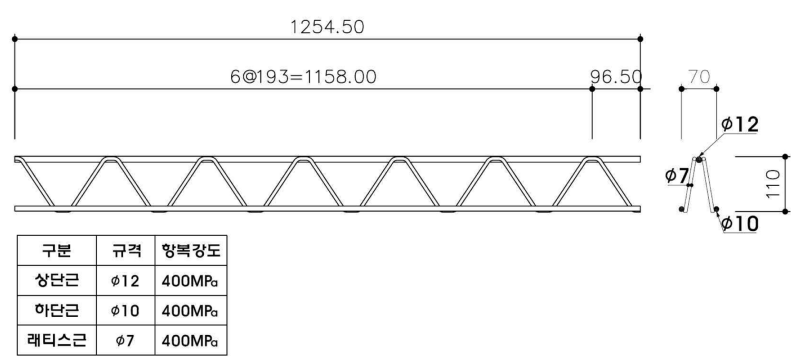

(b) Triangular lattice girder

Fig. 4 Shape of lattice girder

reinforced sleeper, strain and stress distribution were evaluated after applying same load condition as existing triangular lattice girder-reinforced bi-block sleeper applied to HSR.

Bi-block sleeper was evaluated in a way to conform the interaction between concrete and lattice girder using a model integrating concrete and lattice girder and analysis model was carried out by modeling the half of bi-block sleeper for linear static structural analysis and analysis result was compared.

The section was assumed to be composite beam (lattice girder + concrete) in rectangular section comprising concrete thickness including ballast layer (TCL, Track Concrete Layer) which fixes the bi-block sleeper and bi-block width and composite spring coefficient to composite beam floor was applied as boundary condition.

MIDAS-CIVIL 2012 was used as structural analysis software.

\subsubsection{Components of Bi-block sleeper analysis model}

The shape of spiral lattice girder and triangular lattice girder is as Fig. 4 and the material properties are as Table 1.

Analysis model in Fig. 5 was made using commercial software MIDAS-CIVIL. The load condition was defined as Fig. 6, $37.68 \mathrm{kN} / \mathrm{mm}$ was adopted as composite spring coefficient referring to Bundang line (Wangshimri Seolreung) double track breakdown. Elastic coefficient corresponding to Fck 50 Mpa was applied to the section where the concrete was placed in advance and $30 \mathrm{Mpa}$ to the sec-
Table 1 Material properties

\begin{tabular}{cccccc}
\hline \hline $\begin{array}{c}\text { Material } \\
\text { Name }\end{array}$ & $\begin{array}{c}\text { Elastic } \\
\text { Modulus } \\
\left(\mathrm{N} / \mathrm{mm}^{2}\right)\end{array}$ & $\begin{array}{c}\text { Poisson's } \\
\text { ratio }\end{array}$ & $\begin{array}{c}\text { Density } \\
\left(\text { ton/mm } / \mathrm{mm}^{3}\right)\end{array}$ & $\begin{array}{c}\text { Yield } \\
\text { strength } \\
\left(\mathrm{N} / \mathrm{mm}^{2}\right)\end{array}$ & $\begin{array}{c}\text { Concrete } \\
\text { Strength } \\
\left(\mathrm{N} / \mathrm{mm}^{2}\right)\end{array}$ \\
\hline Steel & 205,000 & 0.3 & $7.85 \times 10^{-9}$ & $\begin{array}{c}400,500,60 \\
0\end{array}$ & - \\
Concrete & - & 0.18 & $2.5 \times 10^{-9}$ & - & 30,50 \\
\hline
\end{tabular}

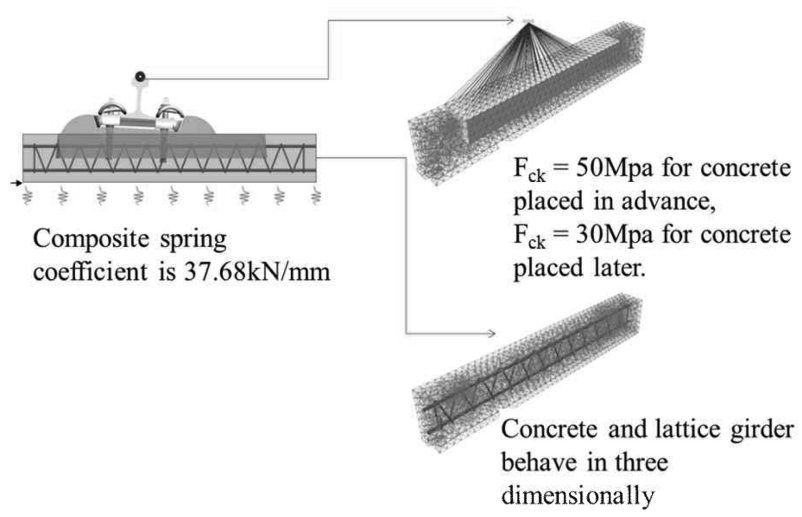

Fig. 5 Finite element analysis model of bi-block sleeper
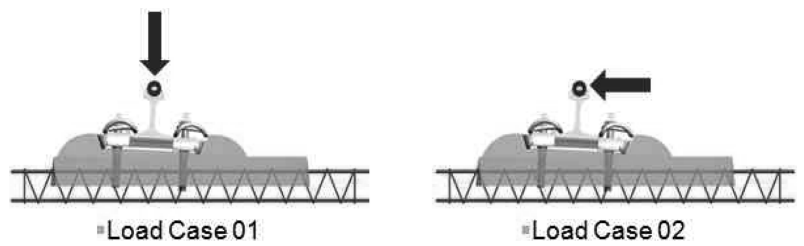

Fig. 6 Finite analysis model

tion to be placed later. Rigid link element was applied to rail location and Solid TETRA to concrete element and for lattice girder, joint was shared using beam element so that concrete and lattice girder behave in three dimensionally. For sleeper weight, self weight in MIDAS was applied and concrete block was disregarded despite of the load $0.3204 \mathrm{kN}$ because of relatively smaller load than others. $62.5 \mathrm{kN}$ was applied as Vertical load (HL25) by applying a single lattice girder and $15.625 \mathrm{kN}$ was applied as horizontal load (HL25) by applying a single lattice girder.

\subsubsection{Analysis result}

As a result of analysis, maximum stress of concrete occurred at the bottom of TCL (Track Concrete Layer) and when assuming maximum stress of triangular lattice girder as $100 \%$, spiral lattice girder was reduced to $68 \%$.

Given TCL concrete strength is $30 \mathrm{MPa}$, it's within the tolerable level and as $50 \mathrm{MPa}$ high strength concrete is used for rail fastening part, it would be safe against wheel 


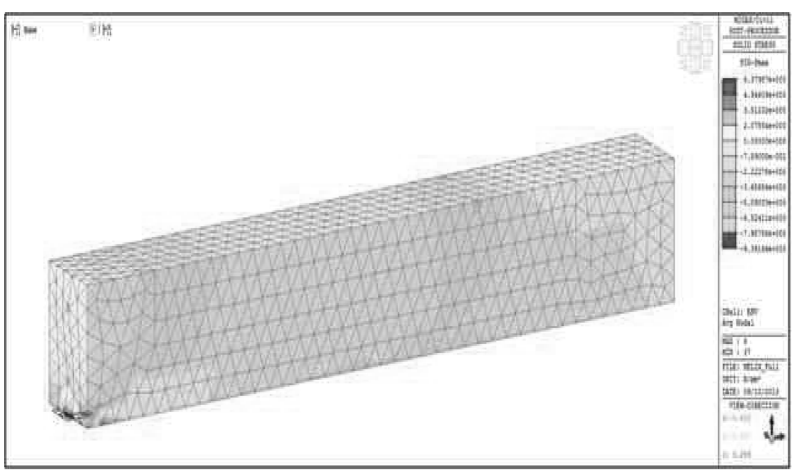

(a) Maximum stress of spiral lattice girder. $9.4 \mathrm{MPa}$

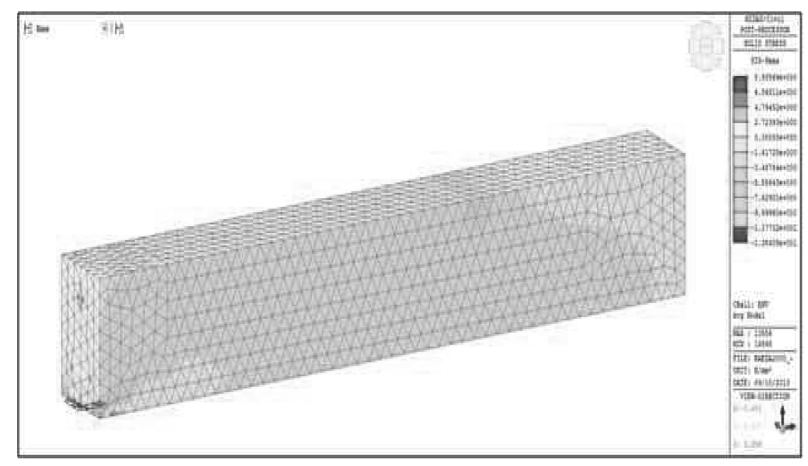

(b) Maximum stress of triangular lattice girder $13.8 \mathrm{MPa}$

Fig. 7 Concrete stress analysis result

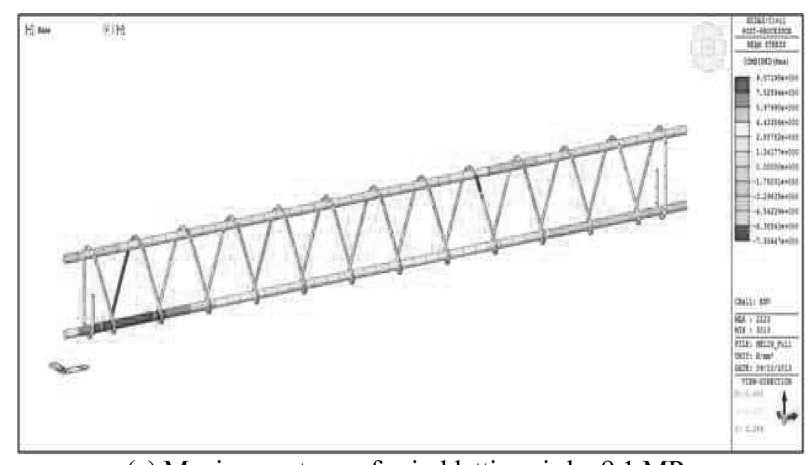

(a) Maximum stress of spiral lattice girder $9.1 \mathrm{MPa}$

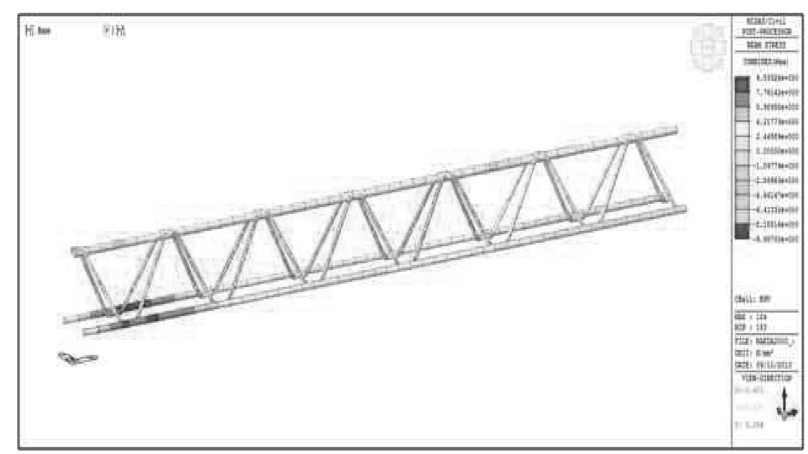

(b) Maximum stress of triangular lattice girder $10.0 \mathrm{MPa}$

Fig. 8 Lattice girder stress analysis result

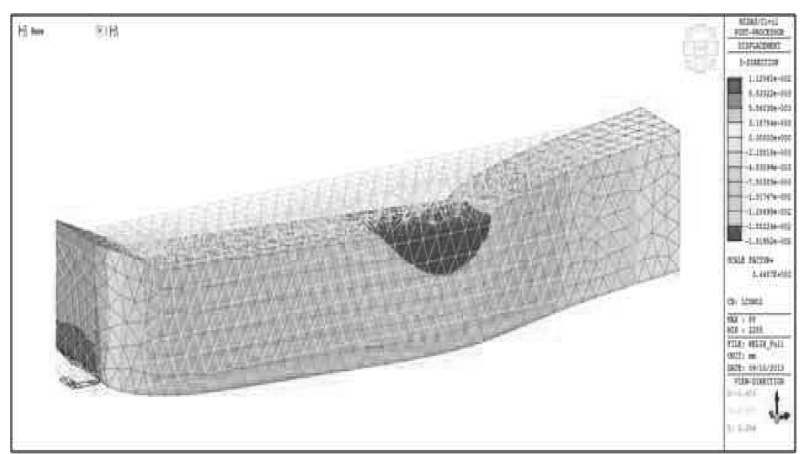

(a) Maximum strain of spiral lattice girder $0.0182 \mathrm{~mm}$

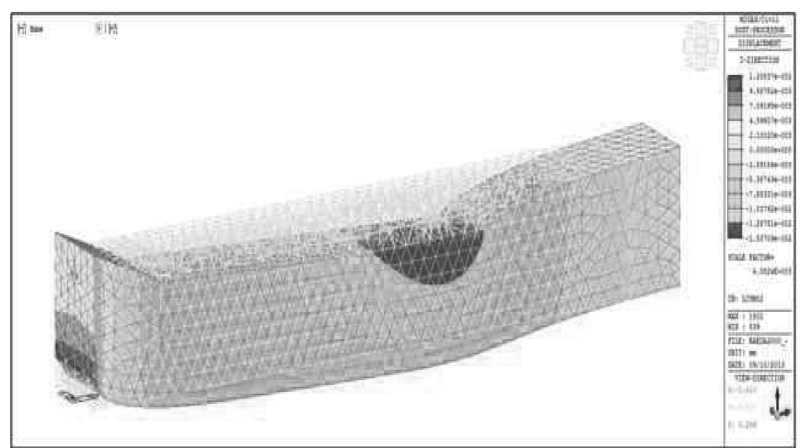

(b) Maximum strain of triangular lattice girder: $0.0154 \mathrm{~mm}$

Fig. 9 Strain analysis result

load. Stress analysis result of concrete is as Fig. 7.

Maximum stress of lattice girder occurred on horizontal reinforcement and when assuming maximum stress of triangular lattice girder as $100 \%$, spiral lattice girder was reduced to $90 \%$.

Maximum stress occurred on horizontal reinforcement of lattice girder was attributable to flexural moment by wheel load. Lattice girder stress analysis result is as Fig. 8.

Strain on sleeper of triangular lattice girder and spiral lattice girder was very insignificant which may be disregarded, which indicated sleeper strain by wheel load was very small and thus the structure is optimal to constrain the concrete crack, extend the service life of sleeper as well as minimize the maintenance.

Interaction between concrete and lattice girder was confirmed using analysis model (finite element model) which integrates lattice girder and concrete.

As a result of comparing spiral lattice girder-reinforced sleeper with existing triangular lattice girder-reinforced sleeper, structural performance was similar satisfying the requirement but spiral lattice girder-reinforced sleeper was improved than triangular lattice girder-reinforced sleeper.

According to the analysis result of spiral lattice girder, conclusion was it has more optimal structure to reinforce concrete reinforcement of spiral lattice girder, which 


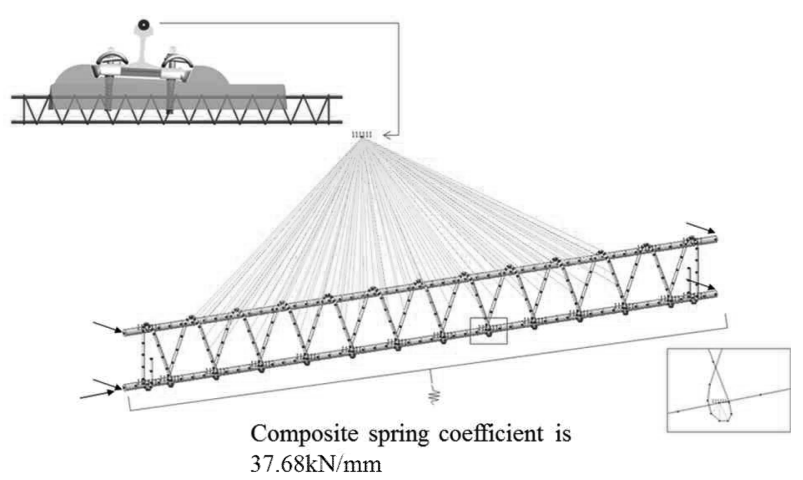

(a) Spiral lattice girder analysis model

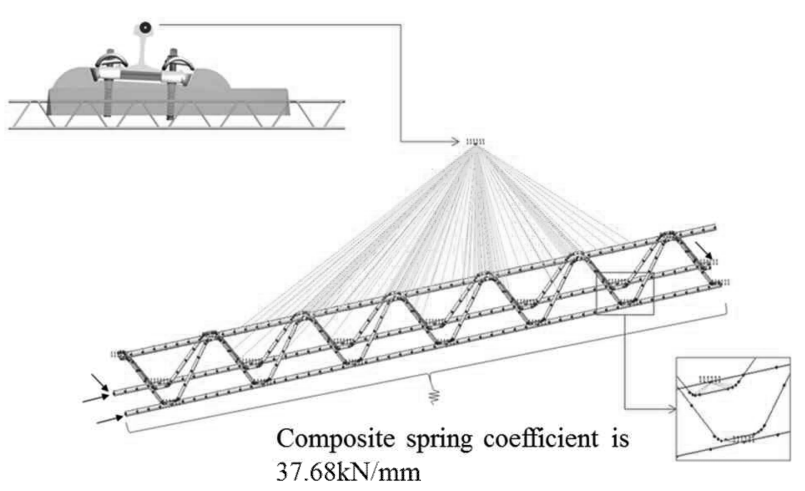

(b) Triangular lattice girder analysis model

Fig. 10 Lattice girder finite element analysis mode

means the new type of spiral lattice girder which will replace triangular lattice girder was developed.

\subsection{Comparison of structural performance of lattice girders}

To compare the structural performance of triangular lattice girder and spiral lattice girder more specifically, structural analysis of lattice girder was conducted separately. A linear static structural analysis was conducted by modeling the half of lattice girder and analysis result was compared.

\subsubsection{Components of analysis model of lattice girder}

The shape of spiral lattice girder and triangular lattice girder is as Fig. 4 and the properties are as Table 1 and load condition as Fig. 6. Analysis model completed is as Fig. 10.

\subsubsection{Analysis model}

When comparing maximum stress on horizontal reinforcement on top and bottom of both lattice girders, maxi-

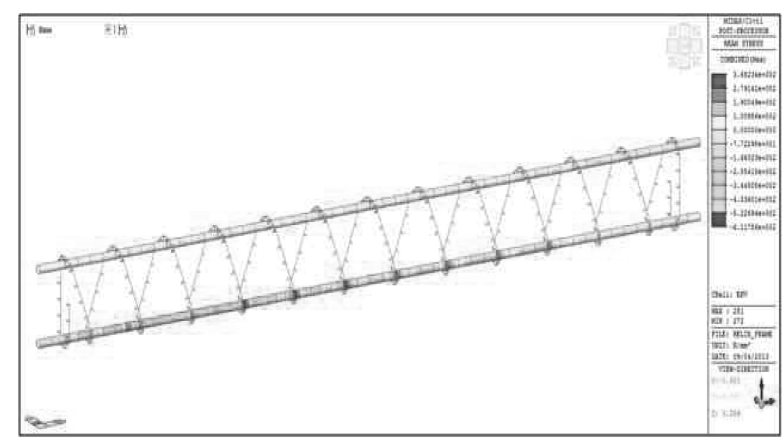

(a) Maximum stress $612 \mathrm{MPa}$ on horizontal reinforcement of spiral lattice girder

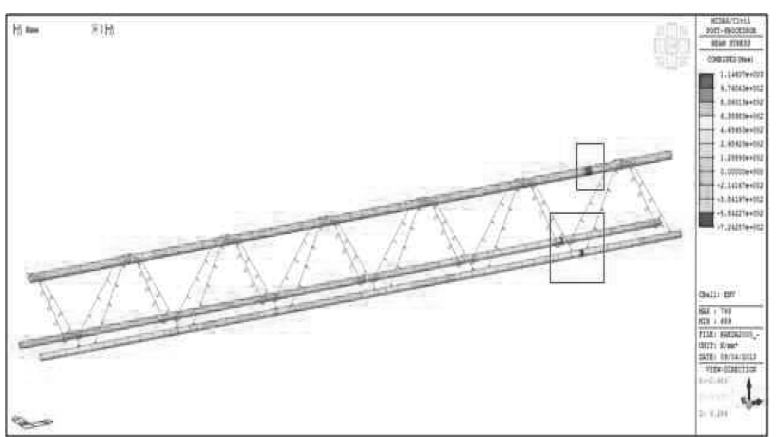

(b) Maximum stress 1,146MPa on horizontal reinforcement of triangular lattice girder

Fig. 11 Maximum stress on horizontal reinforcement

mum stress was occurred in both cases on joint between horizontal reinforcement on top and bottom and lattice and assuming the maximum stress of triangular lattice girder as $100 \%$, maximum stress level of spiral lattice girder was reduced to $53.4 \%$. And on triangular lattice girder, the stress was concentrated on specific point while the stress was uniformly distributed over entire horizontal reinforcement of spiral lattice girder, which indicated spiral latticereinforced sleeper had more improved bending-resistant structural performance and is able to convey greater wheel load. Maximum stress analysis result on horizontal reinforcement on top and bottom of lattice girder models is as Fig. 11.

When comparing maximum stress on horizontal reinforcement of both lattice girders, maximum stress in both cases was occurred on inclined lattice. Assuming the maximum stress of triangular lattice girder as $100 \%$, maximum stress of spiral lattice girder was reduced to $59.3 \%$. And on triangular lattice girder, the stress was concentrated on specific point while the stress was uniformly distributed over entire horizontal reinforcement. Such result was attributable to load dispersion effect of spiral lattice and thus spiral lattice girder when used would distribute 


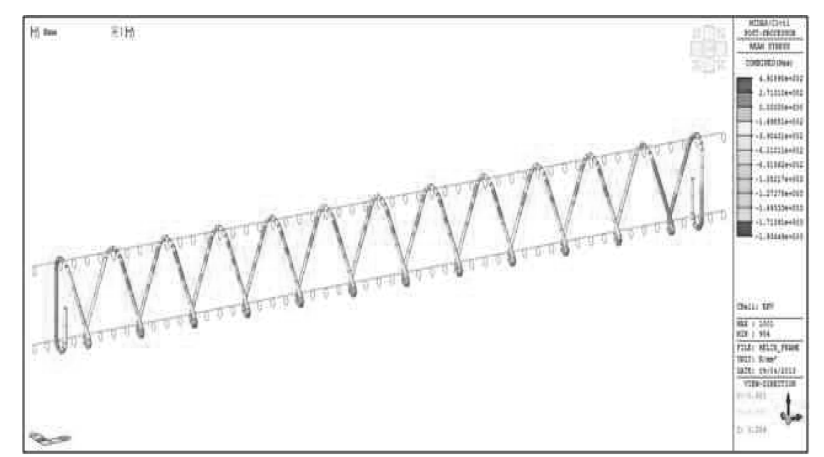

(a) Maximum stress $1,395 \mathrm{MPa}$ on lattice of spiral lattice girder

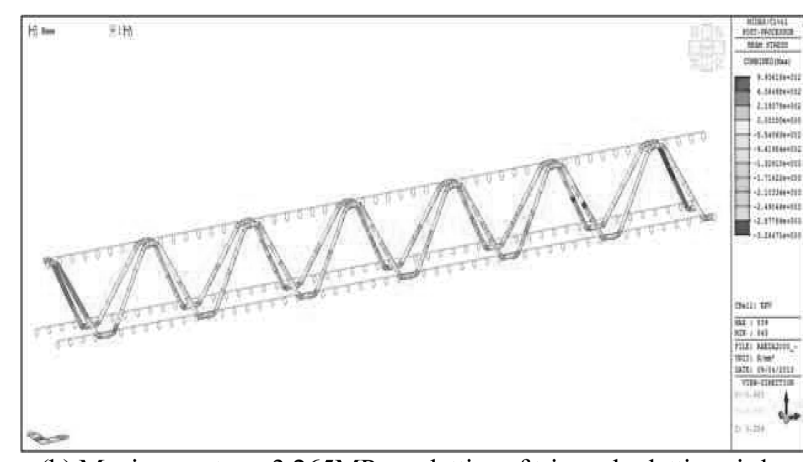

(b) Maximum stress 3,265MPa on lattice of triangular lattice girder

Fig. 12 Comparison of maximum stress on lattice

wheel load uniformly over entire sleeper to the ground which will help enhance the durability of the sleeper. Maximum stress analysis result of lattice girder model is as Fig. 12.

When it comes to maximum strain (deflection), a large strain occurred locally on specific point of triangular lattice girder as indicated in Fig 12, while distributed uniformly on entire part of spiral lattice girder.

Assuming the maximum strain of triangular lattice girder as $100 \%$, maximum strain of spiral lattice girder was reduced to $24.8 \%$. Such small strain (deflection) distributed uniformly over entire part was attributable to load dispersion effect of continuous spiral structure. Thus when a sleeper is reinforced with a spiral lattice girder, strain (deflection) would be significantly reduced and the crack in concrete would be minimized accordingly.

Finite element analysis of a triangular lattice girder used for $300 \mathrm{~km} / \mathrm{h} \mathrm{HSR}$ and a spiral lattice girder proposed for $350 \mathrm{~km} / \mathrm{h}$ was conducted for analysis by comparing. As a result, a spiral lattice girder was found to have had more structural stability. Particularly, spiral lattice-reinforced concrete sleeper showed improved structural performance, conveying greater wheel load than a triangular lattice girder and load dispersion effect of spiral lattice girder enhanced the durability of concrete block and minimized

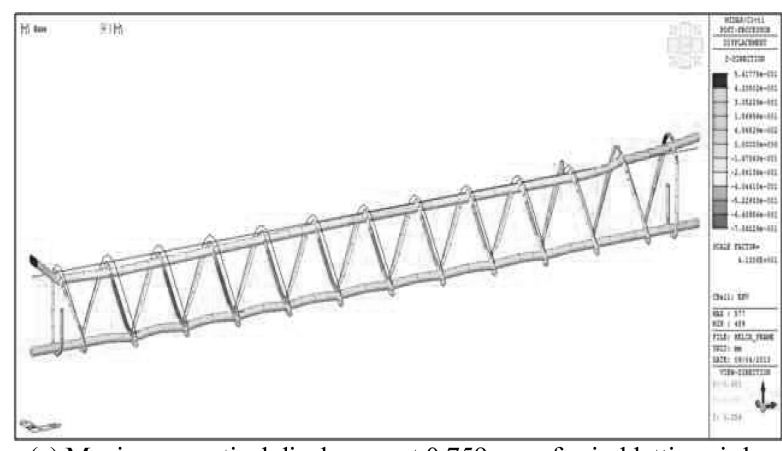

(a) Maximum vertical displacement $0.759 \mathrm{~mm}$ of spiral lattice girder

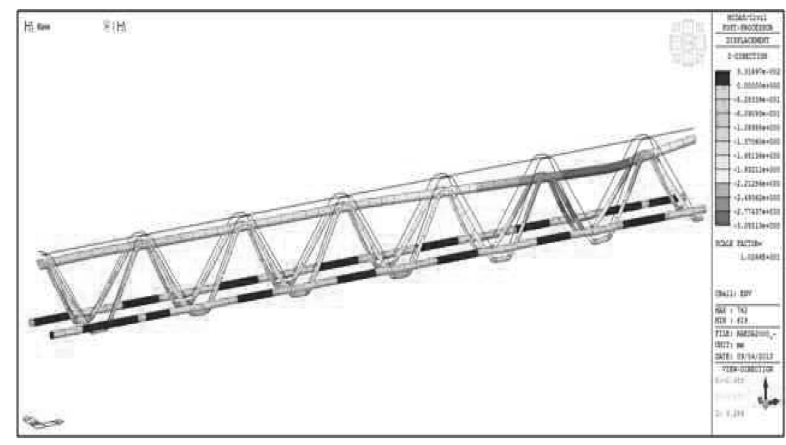

(b) Maximum vertical displacement $3.055 \mathrm{~mm}$ of triangular lattice girder

Fig. 13 Comparison of maximum displacement

the crack in concrete.

Besides, a spiral lattice girder-reinforced sleeper formed a composite core structure by confinement effect while concrete and spiral lattice are integrated, which further enhances the structural performance of concrete sleeper. Thus when applying spiral lattice-reinforced concrete sleeper is used for $350 \mathrm{~km} / \mathrm{h}$ or faster HSR, it would minimize the maintenance effort as well as reduce the life cycle cost (LCC).

\section{Fastener Interface by Improving Lattice Girder Shape (Proposed)}

\subsection{Review of interference with rail fastener}

When applying improved Bi-Block (proposed) no interference occurred as a result of reviewing the interference with rail fastener as seen in Fig. 14.

Interference would possibly be occurred with rail fastener or reinforcement before and after embedding but as no interference occurred when applying a spiral lattice girder, it may replace the triangular lattice girder.

\subsection{Review of insulator interval}

As shown in Fig 15, review of interval of insulator when applying improved Bi-block sleeper was made. 


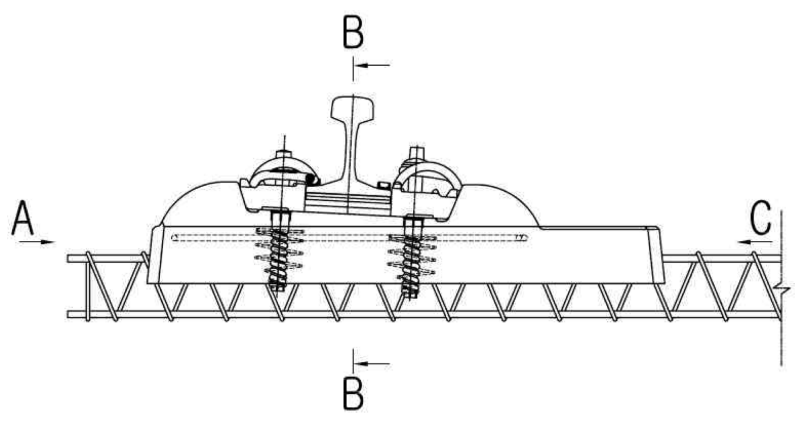

(a) Front view

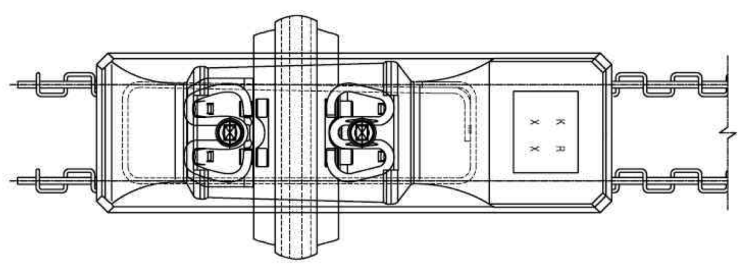

(b) Plan
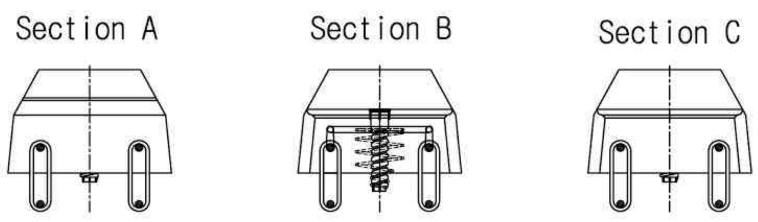

(c) Cross-sectional view

Fig. 14 Review of interference with rail fastener

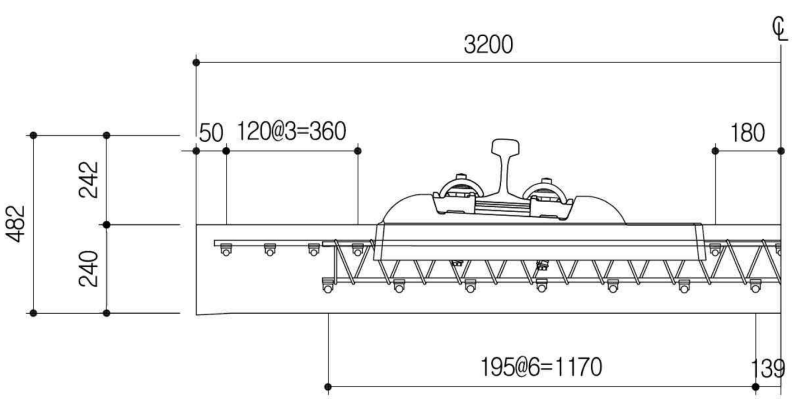

Fig. 15 Review of insulator interval

Though the interval of insulator needed to be adjusted partly, it may be adjusted within the maximum interval $(195 \mathrm{~mm})$ and thus no interference with a spiral lattice.

\section{Review of Constructibility and Cost Efficiency after Improving Lattice Girder}

\subsection{Cost efficiency}

Improvement of Bi-block is intended to enhance the structural performance by modifying lattice girder reinforcing the concrete and thus no significant change in cost
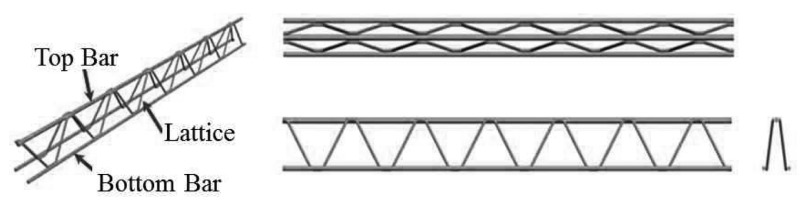

Fig. 16 Shape and members of triangular lattice girder
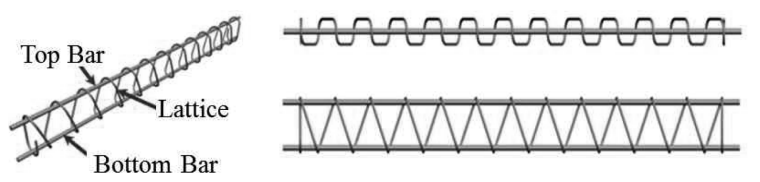

Fig. 17 Shape and members of spiral lattice girder

Table 2 Structural performance of triangular lattice girder

\begin{tabular}{cccccc}
\hline \hline & \multicolumn{5}{c}{ Triangular lattice girder } \\
\cline { 2 - 6 } Category & $\begin{array}{c}\text { Fy } \\
\mathrm{MPa}\end{array}$ & $\begin{array}{c}\text { size } \\
\mathrm{mm}\end{array}$ & $\begin{array}{c}\text { Section } \\
\text { area } \\
\mathrm{mm}^{2}\end{array}$ & $\begin{array}{c}\text { quantity } \\
\text { ea }\end{array}$ & $\begin{array}{c}\text { Allowable } \\
\text { tensile } \\
\text { strength } \\
\mathrm{kN}\end{array}$ \\
\hline Top bar & 440 & $\Phi 12$ & 113.1 & 1 & 49.8 \\
Bottom & 440 & $\Phi 10$ & 78.5 & 2 & 69.1 \\
lattice & 440 & $\Phi 7$ & 38.5 & 2 & - \\
\hline
\end{tabular}

Table 3 Material quantity of triangular lattice girder

\begin{tabular}{cccccc}
\hline \hline & \multicolumn{5}{c}{ Triangular lattice girder } \\
\cline { 2 - 6 } Category & $\begin{array}{c}\text { length } \\
\mathrm{mm}\end{array}$ & $\begin{array}{c}\text { size } \\
\mathrm{mm}\end{array}$ & $\begin{array}{c}\text { Section } \\
\text { area } \\
\mathrm{mm}^{2}\end{array}$ & $\begin{array}{c}\text { quantity } \\
\text { ea }\end{array}$ & $\begin{array}{c}\text { weight } \\
\mathrm{kg}\end{array}$ \\
\hline Top bar & 2,509 & $\Phi 12$ & 113.1 & 1 & 2.23 \\
Bottom & 2,509 & $\Phi 10$ & 78.5 & 2 & 3.09 \\
Lattice bar & 4,000 & $\Phi 7$ & 38.5 & 2 & 2.42 \\
Weight & \multicolumn{5}{c}{ Weight } \\
\end{tabular}

efficiency is estimated.

But as the shape is changed to spiral from triangular pattern, there may be some differences in material volume and cost efficiency was reviewed in such change. And as other material such as concrete and rail fastener, except lattice girder, remain unchanged, no comparison was made with other material.

A triangular lattice to be compared with comprises one top bar, 2 bottom bars and 2 lattices as seen in Fig. 16.

Spiral lattice girder comprises one top bar, one bottom bar and one lattice as seen in Fig. 17.

Structural performance and quantity of triangular lattice girder are as Table 2 and Table 3.

Spiral lattice girder which will replace triangular lattice 
Table 4. Structural performance of spiral lattice girder

\begin{tabular}{cccccc}
\hline \hline & \multicolumn{5}{c}{ spiral lattice girder Case-A } \\
\cline { 2 - 6 } Category & $\begin{array}{c}\text { Fy } \\
\mathrm{MPa}\end{array}$ & $\begin{array}{c}\text { size } \\
\mathrm{mm}\end{array}$ & $\begin{array}{c}\text { Section } \\
\text { area } \\
\mathrm{mm} 2\end{array}$ & $\begin{array}{c}\text { quantity } \\
\text { ea }\end{array}$ & $\begin{array}{c}\text { Allowable } \\
\text { tensile } \\
\text { strength } \\
\mathrm{kN}\end{array}$ \\
\hline Top bar & 550 & $\Phi 12$ & 113.1 & 1 & 62.2 \\
Bottom & 550 & $\Phi 12$ & 113.1 & 1 & 62.2 \\
Lattice bar & 550 & $\Phi 6$ & 28.3 & 1 & \\
\hline
\end{tabular}

Table 5 Material quantity of spiral lattice girder

\begin{tabular}{cccccc}
\hline \hline & \multicolumn{5}{c}{ Triangular lattice girder } \\
\cline { 2 - 6 } Category & $\begin{array}{c}\text { length } \\
\mathrm{mm}\end{array}$ & $\begin{array}{c}\text { size } \\
\mathrm{mm}\end{array}$ & $\begin{array}{c}\text { Section } \\
\text { area } \\
\mathrm{mm}^{2}\end{array}$ & $\begin{array}{c}\text { quantity } \\
\text { ea }\end{array}$ & $\begin{array}{c}\text { weight } \\
\mathrm{kg}\end{array}$ \\
\hline Top bar & 2,509 & $\Phi 12$ & 113.1 & 1 & 2.23 \\
Bottom & 2,509 & $\Phi 12$ & 113.1 & 1 & 2.23 \\
Lattice bar & 7,600 & $\Phi 6$ & 28.3 & 1 & 1.69 \\
& Weifght of triangular lattice girder & 6.14 \\
Weight & \multicolumn{5}{c}{ Weight of required rebar per sleeper } \\
\hline
\end{tabular}

girder uses high strength steel member to secure the structural performance and reduce the quantity and the structural performance was compared with existing spiral lattice girder within the range to satisfy the structural performance evaluation result through structural analysis after setting the combination below.

Top bar was $550 \mathrm{MPa}$ high strength wire in diameter 12 and the quantity of bottom bar was reduced to the half but using 12, $550 \mathrm{MPa}$ high strength wire. Lattice bar diameter was reduced to 6 and the interval was also reduced to the half but using $550 \mathrm{MPa}$ high strength wire. Structural performance of spiral lattice girder is as Table 4.

As a result of comparing the allowable tensile strength of top and bottom bar which convey the flexural moment by wheel load on sleeper, it is increased by $25 \%$ on top bar and decreased by $10 \%$ on bottom bar compared to triangular lattice girder which however were in tolerable range according to structural analysis. As effective shear strength can be secured by effective section of sleeper concrete alone, no shear reinforcement is required and thus lattice bar seemed to serve the spacer to maintain the interval of top and bottom.

When it comes to material quantity, the quantity for spiral lattice girder is about $80 \%$ of those for triangular lattice girder, indicating $20 \%$ reduction (Table 5).

Summarizing the above, replacing the triangular lattice girder with spiral lattice girder would reduce steel member by $3.19 \mathrm{~kg}$ per sleeper in quantity and $W 5,000 /$ piece in construction cost. Besides, royalty cost (5\% of the product price) would be reduced.

\subsection{Constructibility}

As the sleeper is installed in the pattern of Bi-block sleeper RHEDA 2000 or KCT-II which have been applied domestically, no difference in constructibility is expected.

As the shape of block top only varies depending on rail fastener within the scope of Bi-block sleeper, no significant difference from existing method is expected.

\section{Conclusion}

In this study, a Bi-block sleeper reinforced with spiral lattice girder which improves the durability and structural performance of the sleeper was proposed. Spiral lattice structure envelops the concrete inside to generate confinement effect which increases the compressive strength of concrete, thereby upgrading the structural performance. Finite element analysis model was prepared for performance verification so as to compare with the bi-block sleeper reinforced with triangular lattice girder. As a result, spiral lattice girder has less stress and strain than triangular lattice girder which indicated spiral lattice girder have effect of constraining crack in concrete, extending the service life and minimizing the maintenance need. As a result of comparing and analyzing the structural performance of lattice girder alone, stress and strain on spiral lattice girder were less than triangular lattice girder. In addition, interference between spiral lattice girder and rail fastener and interval of insulators were reviewed and as a result, no interference was monitored. When it comes to cost efficiency, spiral lattice girder requires less rebar, resulting in reduction by $\$ 5,000 /$ piece and royalty cost for technical tie-up would also be reduced, and for constructibility, no difference in construction method from existing bi-block sleeper was confirmed.

\section{Acknowledgement}

This study was carried out as part of the research titled, "Development of technology for a trial application of $400 \mathrm{~km} / \mathrm{h}$-grade high-speed rail infrastructure" supported by the ministry of Land, Transport and Maritime Affair.

\section{Reference}

1. Ministry of Land, Infrastructure and Transport (2013). Specification for Railroad Construction Standards.

2. Korea Rail Network Authority (2013). KR CODE

3. Korea Rail Network Authority (2013). Operation and Main- 
Ki-Young Eum / IJR, 6(4), 160-168, 2013

tenance Guideline for Railroad.

4. Korea Rail Network Authority (2012). Research for Maintenance Criteria in Slab Track for High-Speed Line.

5. Korea Rail Network Authority (2012). Design Report for Report for Honam High-Speed Line.

6. Korea Rail Network Authority (2012). Structural Report for Honam High-Speed Line.

7. Korea Rail Network Authority (2008). Operation and Main- tenance Guideline for Honam High-Speed Line.

8. Korea Rail Network Authority (2007). A Study on the Applicability of Standard Specification for Railroad.

9. Korea Rail Network Authority (2002). Performance Specification for Fasteners.

10. Seo, S.B. (2012). "Track Engineering", 3rd Edition, Book Gallery. 